\title{
Exploration on the Training Mode of Engineering Professionals in Agricultural Universities
}

\author{
Yu Shi \\ College of Engineering and Technology \\ Tianjin Agricultural University \\ Tianjin, China \\ syych83@tjau.edu.cn \\ Hua Liu \\ College of Engineering and Technology \\ Tianjin Agricultural University \\ Tianjin, China \\ 41599386@qq.com
}

\author{
Weiyu Zhang \\ College of Engineering and Technology \\ Tianjin Agricultural University \\ Tianjin, China \\ 525156985@qq.com \\ Hongying Sun \\ College of Engineering and Technology \\ Tianjin Agricultural University \\ Tianjin, China \\ 77001580@qq.com
}

\begin{abstract}
Agriculture is the foundation of the country. Cultivating agricultural engineering talents will become an important way to promote the development of agricultural science and technology. The key to improving the core compe titiveness of agricultural modernization is to rely on talents. The key to the growth of talent is to rely on education. The level of talent training is the primary criterion for measuring the quality of higher education, and the completion of tasks and the guarantee of quality are achieved through the talent training model. This article aims to explore agricultural engineering talents training system to meet the needs of agricultural modernization and the individualized needs of students. According to new goals and new normal of regional agricultural development, adjust professional construction ideas and curriculum; establish a practical teaching system and a staged evaluation system; deepen the construction of the teaching staff, in order to realize the cultivation of diversified talents and fields in the large-scale education of undergraduates in agricultural universities.
\end{abstract}

Keywords-agriculture; training system; curriculum

agriculture-related Engineering;

\section{INTRODUCTION}

Agriculture is the root of the country. With the continuous development of information technology, agriculture will become the main battlefield for high-tech competition. The knowledge of environmental sciences, engineering sciences, information sciences, food sciences and other disciplines will infiltration into the field of agricultural science [1]. Relying on talents is the key to improving the core competitiveness of agricultural modernization, and education is the key to the growth of talent. Cultivate talents of agricultural engineering will become an important way to promote the development of agricultural science and technology. Talent Cultivation is the Fundamental Task of Colleges and Universities, the level of talent cultivation is the primary criterion for measuring the quality of higher education. The accomplishment of the task

\footnotetext{
1. Major Education Reform Bidding Project of Tianjin Agricultural University (2017-B-00).
}

2. Key Projects of Tianjin Education Committee (171006101C) and the guarantee of quality are achieved through the talent cultivation mode. The professional cultivation objectives, cultivation plans and cultivation effects will be determined by the personnel training mode [2]. Constructing Talent Training System for Engineering Majors in Agricultural Universities must meet the needs of agricultural modernization and the individual needs of undergraduates. In accordance with the new goals and new normal of regional agricultural development, the orientation of personnel training will be adjusted, which can achieve multi-disciplinary personnel cultivation in the large-scale education of undergraduates in agricultural universities.

\section{PROFESSIONAL SETTINGS AND ABILITY REQUIREMENTS OF THE ENGINEERING MAJORS RELATED TO AGRICULTURE}

Talent service society, social needs are the basis for professional settings, the standard for evaluating talents and the measure of ability. Ensure the development of modern urban agriculture in Tianjin continues to lead the country is Tianjin's modern urban agriculture development goal, which maintains dominance in the fields of facilities and equipment, agricultural science and technology, information technology, quality and safety, and agricultural multi-functionality [3]. Tianjin Agricultural University is the only agricultural university in Tianjin, embracing the important responsibility of training highly-qualified professionals for regional economic development. As an example, considering the needs of agricultural development in Tianjin, combining the needs of agricultural science and technology development and the needs of companies in related industries, the College of Engineering Technology has added two majors: New Energy Science and Engineering and Electrical Engineering and Automation since 2013, to meet the needs of agricultural modernization in the respect of technical personnel in the areas of biomass energy conversion, wind energy utilization, rural power system construction, and transformation of 
agricultural equipment. To cultivate the technical talent for society, through tracking the career development of graduates in the past five years and the feedback from employers, the college has analyzed the competency and requirements required for graduates of the above majors in social and professional fields. In addition to engineering analysis, professional application, training analysis and design capabilities acquired in professional learning [4], we must pay attention to the ability to independently study, analyze and solve complex engineering problems, academic research, innovation and entrepreneurship, and solidarity and cooperation in the cultivation of professional talents. In addition, the combination of solid engineering application capabilities and broad agricultural knowledge reserves is an indispensable link in the training of agricultural professionals.

\section{Professional construction IDEAS}

According to social needs and competence requirements in related professional fields, the College of Engineering Technology established a professional and comprehensive teaching platform based on agricultural engineering disciplines in the construction of four agriculture-related engineering specialties, in order to promote the construction of professional groups and strengthen cooperation among other engineering majors in the university, which can realize resource sharing and complement each other [4]. According to the changes in the structure of agricultural industry and the new situation of Tianjin's modern urban agriculture development goals, the universities should promptly adjust the professional training objectives and training direction. Learn from Nanjing University undergraduate talent fostering system, desalination disciplinary boundaries. In accordance with the different stages of undergraduates' development goals, formulate a multi-category talent training model that meets the requirements of agriculture-related professional construction based on the philosophy of general education and personalization to respond to the changing needs of the market for skilled talents in agriculture.

\section{CAPABILITY ACQUISITION SURVEY OF UNDERGRA DUATES}

Distribute questionnaires to track undergraduates' learning and living conditions while they are in school. The survey includes information on the teaching behavior of the teacher, the professional identity of the student, the ability of career decision-making, the preparation of job hunting, the mastery of occupational skills, the compatibility of the current training program and the need for professional competence. The respondents were four students in the college who were freshmen and senior students. The survey process shows that students participate in the survey more passively. This shows that a considerable number of students are unwilling to actively think about the gap between the professional learning situation and the analysis of their own professional abilities and practical requirements, which leads to a delay in the planning of career choices. Undergraduates have individualized differences in their work prospects, mastery of vocational skills, and ability improvement. The results of the survey show that the training of professionals involved in agricultural engineering must focus on professionalism as well as individual needs. Talent Training Should Pay Attention to the Teaching of Cross-discipline Knowledge of Agricultural Basics. In the training of talents, we must pay attention to the teaching of interdisciplinary knowledge of agricultural foundations. Integrate engineering technology, information technology and testing technology into agricultural technology, stimulate and cultivate students' self-learning enthusiasm, and encourage teachers to teach in their own areas of strength.

\section{CONSTRUCTION OF TRAINING MODE FOR LARGE-SCALE TALENTS IN AGRICULTURE-RELATED ENGINEERING MAJORS}

\section{A. Formulate large-scale training programs for agriculture- related engineering majors}

Learn from Undergraduate Teaching Model of Nanjing University, Formulate a large-scale diversified knowledge structure talent training program for agricultural engineering disciplines, based on the professional training program of the four existing undergraduate majors. The principle of engineering practice ability, the teaching model, teaching content, teaching method and curriculum system will be reformed according to the major disciplines. The training of talents is divided into three stages: general education, professional education and multi-cultural training. The experimental class members were screened by conducting a comprehensive ability and English proficiency test for freshmen. Different from other ordinary classes divided by profession, the curriculum of the experimental class is based on the Agricultural Electrification and Automation Experimental Teaching Center and the Student Center for Innovation and Entrepreneurship. Based on the educational philosophy of integrating general education with individualized training, weak down the professional concept, broaden the professional foundation, and formulate a talent training model with the goal of diversified training. Guide students to build their own professional knowledge system. Clarify the professional theoretical level and practical work ability of the experimental class students who have graduated for about 5 years. 


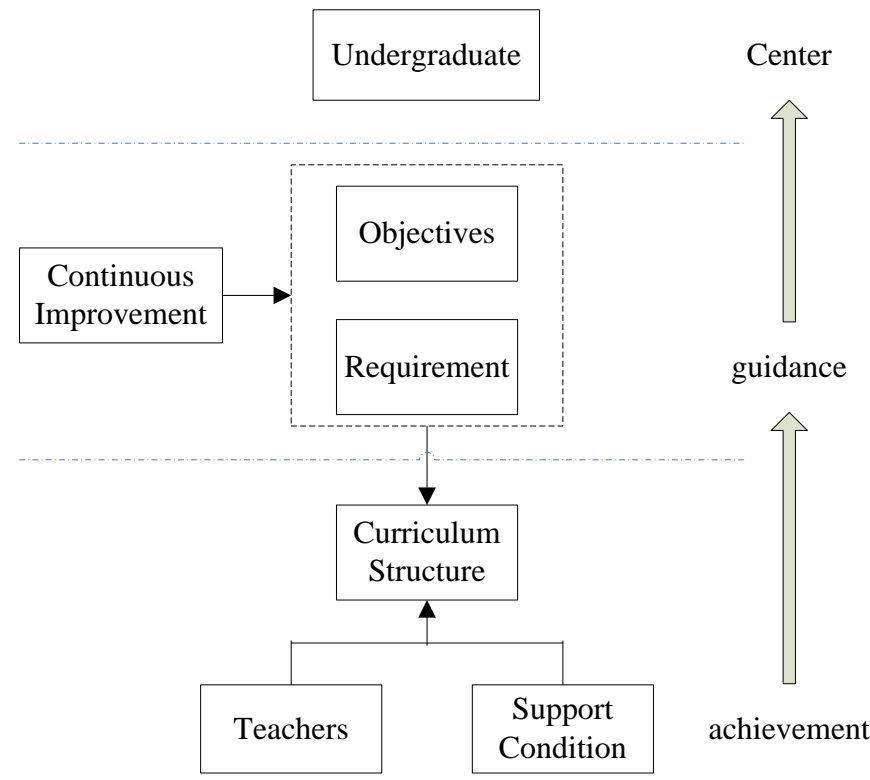

Fig. 1. Diversified personneltraining implementation plan

\section{B. Curriculum}

Through the individual comprehensive quality ability test and the English proficiency test, 30 independent screening students were selected in the freshmen. In the general education stage, public classes are set according to the school start plan. This phase of the training program will open a large number of professional foundation courses in agricultural engineering disciplines. Students in the experimental class are required to complete the public courses and professional basic course credits in the training program. According to the situation of the expansion of the curriculum construction, the teachers revised the construction plan and tried it out in the elective mode of each class.

In the professional training stage, students complete their own courses and the core professional courses of the selected majors according to the professional semester start-up plan in the multi-disciplinary training program.

In the multi-culture stage, students should further clarify their own development direction and complete the credits for this major. Choose the most suitable individualized channel in the three development paths of "discipline competition class", "scientific research class" and "employment and entrepreneurship class". Obtain the "degree certificate” and "vocational qualification certificate" for the corresponding majors.

\section{Construction on Practice teaching system}

Based on the Agricultural Electrification and Automation Experimental Teaching Center, independent professional courses are offered. Construct a practical teaching system that meets the goal of diversified personnel training. Formulate an implementation plan for students to choose their own courses. Set up professional courses, comprehensive design experimental courses and diversified ability development courses for all majors open to the experimental class. Divide the diversified ability development curriculum into three categories: engineering practice, scientific research, and innovative design. Choose to use "discipline competition", "scientific research", "employment and entrepreneurship" as the training goal of the expansion course. According to their own expertise, each professional teacher chooses to expand the course direction and apply to the college for course construction. The approved construction curriculum incorporates a diversified capacity development curriculum system. Teachers carry out undergraduate teaching in their own field of strength.

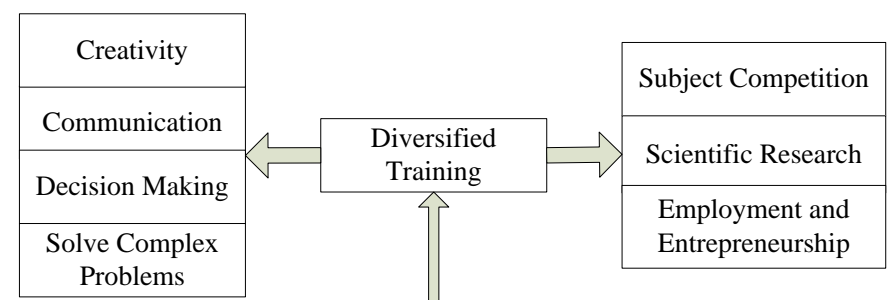

\begin{tabular}{|c|c|c|}
\hline $\begin{array}{c}\text { Experimental Design } \\
\text { and Information } \\
\text { Processing }\end{array}$ & $\begin{array}{c}\text { Professional } \\
\text { Laboratory }\end{array}$ \\
\hline $\begin{array}{c}\text { Design and } \\
\text { Development }\end{array}$ & $\begin{array}{c}\text { Off-campus } \\
\text { Internships }\end{array}$ \\
\hline Problem Analysis & $\begin{array}{c}\text { Professional } \\
\text { Training }\end{array}$ \\
\hline
\end{tabular}

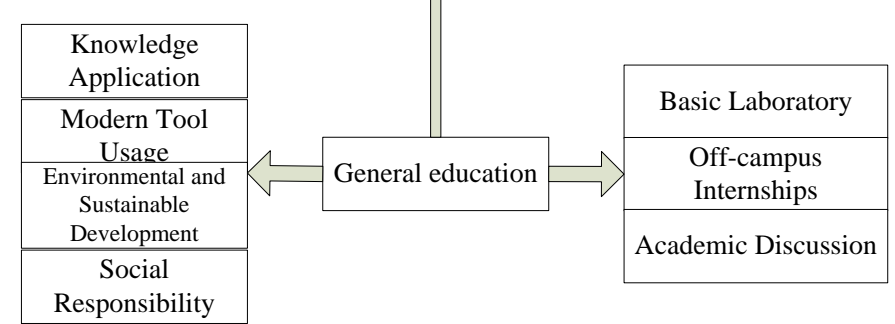

Fig. 2. Diversified Talent Training Model Design

\section{The construction of teachers in the background of diversified personnel training}

According to professional construction needs, taking the construction of a high-level talent team as a starting point, guided by academic excellence, innovation and competitiveness, taking the academic leader as the core, adhere to the principle of combining stability, training and introduction. Increase the introduction of high-level talents and attach importance to the cultivation of talents in excellent disciplines. Increase the potential of young and middle-aged academic leaders to train, attach importance to and encourage young teachers to continue their studies and improve the practical teaching and innovation ability of scholar. Adhere to foreign cooperation and create more environments for young teachers to improve their engineering practice. Establish an effective mechanism to optimize the teaching staff and improve the overall quality of the teaching staff combine use 
with culture. Build a diversified professional faculty with reasonable structure, high academic level, strong research and innovation ability, and outstanding practical teaching ability.

\section{EsTABLISH A STAGED EVALUATION SYSTEM}

Formulate the selection methods for the students in the experimental class, establish a phased evaluation system for the students in the experimental class, and determine the "professional standard" for the professional training stage. Students are required to take a minimum of $80 \%$ of the professional credits in the professional training stage (as a professional standard). If the professional standard is not met, it will be transferred to the regular class in the third year of university. According to the training results of the first stage, the training program was revised.

\section{CONCLUSION}

Through the general education of the major categories of disciplines and the individualized training of diverse knowledge structures, multi-education is implemented in stages according to the different stages of student development. Help students build a diverse knowledge structure by providing students with free choice of courses and an open talent development path that selects the direction of professional development. Clarify the professional theoretical level and practical ability of student graduates to work for 5 years.

\section{ACKNOWLEDGMENT}

This work was financially supported by the Major Education Reform Bidding Project of Tianjin Agricultural University (2017-B-00) and Key Projects of Tianjin Education Committee (171006101C) .

\section{REFERENCES}

[1] Tang Xin. Integration of agriculture and agriculture-related engineering and technical engineering expertise to run[J]. Hunan Agricultural Machinery, 2011,38(07), pp:153-155.

[2] Cao Aifeng. Research on the Undergraduate Training Model of Nanjing University (1984-1996) [D]. Nanjing University, 2013.

[3] Mao Kejun, Fan Min, Chen Xidan. New Thinking, New Goal and New Measures of Tianjin Modern Urban Agriculture's under the Economic New Form Phase [J]. Tianjin Agricultural Sciences, 2015,21(7), pp:1-6.

[4] Zhang Manqing, Wang Jing, Li Guiling, Huang Ying. Research on the Construction of Agriculture-related Professional Groups Based on Beijing Urban Agriculture [J]. Heilongjiang Animal Science and Veterinary Medicine,2016(22), pp:25-27.

[5] Yu Tingjie. The Selection of Professional Orientation: Teacher Education Curriculum Design Influenced by Australian Professional Standards for Teachers [J]. TSINGHUA Journal of Education, 2016, 37(6), pp:46-52.

[6] Jiang fan, Zhang Chunliang. The Construction of Training System for Active Practice Ability of Students in Mechanical Engineerin [J] Research in Higher Education of Engineering, 2016(1), pp:187-192. 